Experimental Child Psychology

Elsevier Editorial System(tm) for Journal of

Manuscript Draft

Manuscript Number: JECP-D-15-00202R2

Title: Building Emotion Categories: Children use a Process of Elimination When they Encounter Novel Expressions

Article Type: SI:Language and Cognition

Keywords: facial expressions; emotion; children; process of elimination

Corresponding Author: Ms. Nicole L Nelson,

Corresponding Author's Institution: University of Queensland

First Author: Nicole L Nelson

Order of Authors: Nicole L Nelson; James A Russell

Abstract: Recent research has indicated that language provides an important contribution to adults' conceptions of emotional expressions and their associated categories, but how language influences children's expression category acquisition has yet to be explored. Across two studies, we provide evidence that when preschoolers (2-4 years) encounter a novel label, they use a process of elimination to match it with its expected expression. Children successfully used a process of elimination to match a single expression to one of several labels (Study 1), and matched a single label to one of several expressions (Study 2). These data highlight one possible mechanism children may use to learn about the expressions they encounter, and may shed light on the ways children's expression categories are constructed. 
February 18, 2016

Dr. Nivedita Mani

Guest Editor

Journal of Experimental Child Psychology

Re: Ms. Ref. No.: JECP-D-15-00202R1

Title: Building Emotion Categories: Children use a Process of Elimination When they Encounter Novel Expressions

Dear Dr. Mani,

Thank you for the opportunity to revise our manuscript. We appreciate the thoughtful and insightful comments from both you and the reviewers. We have now revised the text, incorporating each of your suggestions and outlining the changes in the attached letter with our responses in italicized text. We believe the manuscript is much improved, and hope this version is ready for publication.

Sincerely,

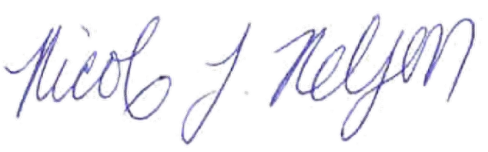

Dr. Nicole Nelson

School of Psychology

University of Queensland

St Lucia, QLD, 4072, Australia

n.nelson@uq.edu.au 
Ms. Ref. No.: JECP-D-15-00202R1

Title: Building Emotion Categories: Children use a Process of Elimination When they Encounter Novel Expressions

Journal of Experimental Child Psychology

Dear Ms. Nicole L Nelson,

Your manuscript has now been read by the two reviewers who also reviewed the original version of the manuscript. As you can see, both reviewers are now more optimistic about the publication of the manuscript with one remaining concern from Reviewer 2, namely the contribution of Study 3 to the manuscript. I tend also to agree with this reviewer since, as you yourselves note, Study 3 did not provide conclusive evidence for the question originally intended to be answered here. I wonder, therefore, whether it would not be better indeed to remove this study from the manuscript. This is especially given the very relevant critique raised by Reviewer 2 regarding interpretation of this study, namely, whether children knew the word "proud" or as even you interpret it, whether children are indeed familiar with the situational information related to pride. Both of these are questionable which leaves the issue open as to the extent to which this study differs from Study 1 and 2 . While I do not require you to remove Study 3 from the manuscript, I do believe you need to more adequately address children's familiarity with the word and the situational information associated with pride. If you cannot do this more convincingly, then I believe excluding Study 3 is the more sensible way to go. This would nevertheless leave open the concern as to the mechanisms underlying children's responding (as also raised by Reviewer 1) in this study as outlined by Reviewer 2's response to your comment on Study 3 (see review below).

Thank you for these comments. As you suggest, we have removed Study 3 from our manuscript.

Reviewers' comments:

Reviewer \#1: I remain enthusiastic about this manuscript. The studies are clever and convincingly show that children use a process of elimination to pair a word with a novel facial expression. Although the specific mechanism underlying this effect remains in question, this is convincing evidence that children do not already readily recognize a set of specific, basic categories. Rather, the authors provide evidence for a flexible mapping between expressions and words across development. I find the manuscript even stronger following the authors' revisions and the fortification of the findings with additional non-parametric analyses.

Thank you. We hope readers find these studies informative as well.

The authors adequately addressed my comments on the previous manuscript and I do not have additional comments.

(Full text provided by the Editor) The only outstanding issue is that the authors were not sure what I meant by one of my previous comments. It was a minor point, but I will reiterate it since it relates to their description of the basic emotion view. My comment regarded the fact that the authors state, "Human beings are subject to a small number of basic emotions..." My initial comment was that this was a strange phrase. According to an online dictionary, "subject to" means, "being dependent on or conditional on something." Thus, I'm not sure that the authors actually mean "subject to" but rather something like "human beings possess" or "are endowed with" a small set of basic emotions.

The reviewer's full comment was not included in our letters, due to a technical glitch, but the editor has provided us with the full text. We are happy to alter this sentence, and it now reads "Human beings are endowed with...".

Reviewer \#2: JECP-D-15-00202R1 Title: Building Emotion Categories: Children use a Process of Elimination When they Encounter Novel Expressions 
I have read one version of this manuscript previously. I find the new version to be much improved in most respects, but one major point concerning study 3 remains.

Thank you, we agree that the suggested revisions have made the manuscript stronger.

Original comment: I do not understand the authors' reasoning that led them to conduct study 3 . I do not believe that this study yields more insight into whether "learning novel labels" or whether they are just matching novel labels to novel facial expressions. From the description in the paper, I assume that the puffed-cheeks images were used together with the label "proud" in this study. I therefore must assume that the authors hypothesis was that (a) participants know the meaning of the word "proud" and (b) should therefore answer the choicefrom-array task, i.e. the question "Do you see anyone who feels proud?" with "no" (presented with a happy, a sad and the puffed-cheeks expression). This did not happen - children were just about as likely to select the puffed-cheeks expression in this task as the children in study 2 (where the label was novel). This leaves two explanations - (a) the children did not know the label "proud", so study 3 is the same as study 2 or (b) the children knew the meaning of "proud", but simply select the puffed-cheeks expression on the basis of its being novel. The low response rates for "proud" in the story labeling task (6\%) to me indicates that the children simply did not know the meaning of "proud", implying that this study adds nothing beyond the data presented in studies 1 \& 2 .

Authors' Reply: The Story Labeling Task was not intended to indicate whether children are familiar with the label proud, but to determine whether children who were familiar with the situational information related to pride would be less likely to link the novel label with the expression of pride. As the data showed, however, children did not link the situation to the concept of pride, so we could not answer our intended question, but this does not mean that children are unfamiliar with the label of pride. Past research has shown that preschoolers are familiar with concepts related to the label proud, including the fact that it is positively valenced (Russell \& Paris, 1994), and that it is associated with expressions (Nelson \& Russell, 2012; Tracy, Robins, \& Lagattuta, 2004) and successful actions (Garcia, Janis \& Flom, 2015). This literature indicates that children are familiar with concepts related to pride, but may not have reached an adult-like understanding of the concept. In the case of our data, although adults viewed the story as indicating pride (rather than happiness), young children viewed it as indicating happiness. This suggests that preschoolers have yet to link situational information to the label proud. We have clarified this issue in the introduction for Study 3. However, we can see how the information related to the Story Labeling Task would be distracting to readers; we have moved reference to this task to the Supplemental Materials.

Reply: I don't agree with the authors here. To adults the story is clearly aimed at the concept of "pride". Children in this study did not share this interpretation. Even if they are familiar with the label "proud", they clearly do not have the same representation of it. Perhaps this was just the case for the particular sample of children tested here, given the literature references the authors provide in their reply. However, I think ignoring the labelling task and simply assuming that they know the label "proud" is the wrong way to go here.

I suggest the authors remove Study 3 from the paper. I think the intention behind conducting it in the first place is unclear. If children know what "proud" is, why would they match a novel facial expression to it which in real life has nothing to do with the concept of proud? Even if the authors had only found evidence pointing in the intended direction, that would have left me wondering how to interpret the results. Together with the evidence pointing towards children not actually knowing the word "proud" this means that Experiment 3 only makes the paper more confusing.

We have elected to remove Study 3 from the paper. We hope this version of the manuscript is clearer. 
Running head: BUILDING CATEGORIES

\title{
Building Emotion Categories: Children use a Process of Elimination \\ When they Encounter Novel Expressions
}

\author{
Nicole L. Nelson, University of Queensland \\ \&
}

James A. Russell, Boston College

Author Note

This research was supported by a grant from the National Science Foundation: No. 1025563 awarded to James A. Russell.

Address correspondence to Nicole L. Nelson, School of Psychology, University of Queensland, St Lucia, QLD, 4072, Australia. E-mail: n.nelson@uq.edu.au. Phone: (61) 73365 6427.

We thank Marissa DiGirolamo for her assistance managing and conducting these studies, and Kerrie Pieloch and Matthew Williams for their help in constructing the stimuli for this project. 


\begin{abstract}
Recent research has indicated that language provides an important contribution to adults' conceptions of emotional expressions and their associated categories, but how language influences children's expression category acquisition has yet to be explored. Across two studies, we provide evidence that when preschoolers (2-4 years) encounter a novel label, they use a process of elimination to match it with its expected expression. Children successfully used a process of elimination to match a single expression to one of several labels (Study 1), and matched a single label to one of several expressions (Study 2). These data highlight one possible mechanism children may use to learn about the expressions they encounter, and may shed light on the ways children's expression categories are constructed.
\end{abstract}

Keywords: facial expressions; emotion; children; process of elimination 


\section{Building Emotion Categories: Children use a Process of Elimination When they Encounter Novel Expressions}

Human beings categorize the emotional events they experience, witness, or discuss. Where do the categories for emotions come from? The theory that the categories are simply innate - and therefore universal - does not adequately explain the complex developmental progression of children's emotion category understanding. Here we explore an alternative mechanism: children use a process of elimination to build new categories when they encounter an emotional event while hearing a novel label.

According to one prominent theory (Ekman \& Friesen, 1978; Izard, 1994), human beings are endowed with a small number of basic emotions (happiness, sadness, anger, fear, surprise, and disgust), which universally, innately, and automatically cause facial expressions, and these facial expressions have a meaning that is similarly universally, innately, and automatically recognized. Recognizing the meaning of one of these facial expressions is pre-linguistic and unaffected by variations in spoken language (Ekman, 1980; Izard, 1971; Tracy \& Matsumoto, 2008). Researchers in this tradition suggest that pre-verbal infants recognize the meaning of the facial signals (Kobiella, Grossmann, Reid, \& Striano, 2008; Izard, 1994; Martens, Hamlin \& Tracy, 2013).

There are reasons, however, to doubt this theory. Research with adults has shown that facial expressions themselves show cultural variation (Marsh, Elfenbein \& Ambady, 2003; Jack, Blais, Scheepers, Schyns \& Caldera, 2009), as does expression interpretation (Gendron, Roberson, van der Vyver \& Barrett, 2014; Nelson \& Russell, 2013; Russell, 1994). Some have pointed to differences in the emotion categories lexicalized in various languages and hence to the influence of language in creating the emotion categories we assign to facial expressions. 
Wierzbicka (1997) suggested that emotion categories were created by the labels each culture uses to describe them. Recent research suggests that participants' expression recognition performance is higher when they are tested in their native language (Kayyal \& Russell, 2013), and lower when their access to a particular emotion label is blocked, using a semantic satiation technique in which the repetition of a particular emotion word (e.g. fear) interferes with recognition of the associated facial expression (Gendron, Lindquist, Barsalou \& Barrett, 2012; Lindquist, Barrett \& Bliss-Moreau \& Russell, 2006). Finally, patients with semantic dementia show a specific deficit in categorizing emotional expressions, but show no deficit in perceiving the underlying valence of the expressions (Lindquist, Gendron, Barrett, \& Dickerson, 2014). These new lines of inquiry suggest that labels are more central to our expression knowledge than has been previously acknowledged (Lindquist, Satpute, \& Gendron, in press; Roberson, Damjanovic, \& Kikutani, 2010).

Evidence that basic emotion categories are recognized by infants and therefore before emotion labels are known (Kobiella, Grossmann, Reid, \& Striano, 2008; Izard, 1994) has also been challenged. Available experimental paradigms cannot determine whether infants are attending to the emotional meaning conveyed by the face or simply discriminating physical features (Quinn et al, 2011). Complicating the picture of development, other researchers have pointed out that children's expression recognition is a protracted process, lasting into middle childhood (Gao \& Maurer, 2010; Herba, Landau, Russell, Ecker \& Phillips, 2006; Roberson, Damjanovic, \& Kikutani, 2010; Widen, 2013; Widen \& Russell, 2004, 2010). For example, it is not until 9 years of age that the majority of children label the "facial expression of disgust" as disgust (Widen \& Russell, 2010a). Moreover, young children do not begin with adult-like categories, one for each basic emotion. Instead, their emotion categories reorganize, shifting 
gradually from simple valence-based categories to more differentiated, adult-like categories (Widen \& Russell, 2003, 2010b). For example, preschooler's concept of sadness includes expressions intended to convey sadness, but also other negative expressions such as those intended to convey anger, fear, embarrassment, shame, and compassion (Widen, 2013; Widen \& Russell, 2002, 2010b). It is only when children reach 4 years of age that anger and fear are excluded from this broad sad category, and not until after 7- to 8-years of age that the sad category is further differentiated into separate categories for embarrassment and shame.

From the perspective of the standard theory, the slow, gradual acquisition of adult-like emotion categories is a puzzle. If an infant automatically knows which facial expressions signal which emotions, then the child's task would be simple: acquire the language community's label for that emotion, and ignore all expressions that do not signal emotions. We are developing a different perspective on the task facing the child. We suggest that the child must learn which facial expressions signal an emotion and which do not, and must learn how to divide emotions into different categories. If so, then the child's overall task can be seen to be much more difficult. Categories of facial expression must be acquired; categories of emotion must be acquired, and the two must be mapped onto one another.

The present study presents evidence on a key aspect of our account. Here we show that the child can form categories from facial expressions no one has suggested signal emotions. We offer evidence that children can rapidly acquire a label but that they do so for novel facial expressions as readily as for those purported to signal a basic emotion. Across two studies, we show that when confronted with an emotion label and facial expression, the child uses a process of elimination to acquire a new expression category. 
Our hypothesis is consistent with research showing that children use a process of elimination to construct a variety of other categories, including learning about novel colors (Carey, 1978), objects (Au \& Markman, 1987; Baldwin, Markman, Bill, Desjardins, Irwin \& Tidball, 1996; Graham, Nilsen, Collins \& Olineck, 2010; Grassman, Stracke \& Tomasello, 2009; Halberda, 2006; Jaswal \& Hansen, 2006; Markman, 1990; Markman \& Wachtel, 1987), animals (Au \& Glasman, 1990; Bialystok, Barac, Blaye \& Poulin-Dubois, 2010), verbally provided facts (Diesendruck \& Markson, 2001; Waxman \& Booth, 2000), adjectives (Diesendruck, Hall \& Graham, 2006; Waxman \& Booth, 2001; Waxman \& Markow, 1998), and actions (Haryu, Imai \& Okada, 2011; Waxman, Lidz, Braun \& Lavin, 2009).

To determine whether children use a process of elimination to associate a facial expression with a label, we conducted two studies. In Study 1, children were presented the labels happy, sad, and pax and asked to match one label to the facial expression presented, or to say that none of the labels applied. The facial expressions presented were positive (happy), negative (sad), and novel (puffed cheeks). Past research indicates that children match happy and sad expressions with their appropriate labels by two years (Widen, 2013). If, as we hypothesized, children use a process of elimination to match the novel label with the novel expression, then children should show agreement in matching the label pax to the puffed cheeks expression. Study 2 reversed the task. Children were shown an array of three expressions (the same expressions used in Study 1) and asked to point to the one showing a certain emotion, designated by a label. To test whether children had acquired the new face-label association, all studies also included a subsequent free labeling task. If children use a process of elimination to match novel expressions with novel labels - as they do when learning about other categories like color - then children should rapidly associate the novel face with the novel label in the word list 
and choice-from-array tasks, and spontaneously label the novel expression with the expected label in the free labeling task.

\section{Study 1}

In daily life, a parent might ask, “do you think taking your brother's toy made him happy or sad?" Such questions provide children the opportunity to match another's expression to one of several provided labels. In this study, we mimicked this process. Children viewed three facial expressions one at a time: happiness, sadness, and puffed cheeks. For each expression, children were asked if the person was feeling happy, sad, or pax (or tolen, in half of the cases). The dependent measure was whether children matched the novel label and expression. As a final trial, children freely labeled each expression to determine whether the associations made between the novel expression and label would be applied in a subsequent task.

\section{Method}

Participants. Participants were 24 children, with 8 children in each of three age groups:

Two-year-olds $(\mathrm{M}=32.8$ mos., $\mathrm{SD}=1.8$ mos. $)$, Three-year-olds $(\mathrm{M}=41.9$ mos., $\mathrm{SD}=3.0$ mos.), and Four-year-olds $(\mathrm{M}=54.8$ mos., $\mathrm{SD}=2.9$ mos. $)$. Each age group included an equal number of males and females. All children were fluent in English and tested in the greater Boston area. In addition, two adult comparison groups $(\mathrm{N}=20)$ evaluated the materials for this study.

Materials. One female and one male adult each posed expressions of happiness, sadness, and an expression not previously associated with any emotion: a puffed-cheeks expression $($ Figure 1)(Action Unit $=34 ;$ Ekman \& Friesen, 1978). One adult comparison group $(\mathrm{N}=10)$ was asked to rate the puffed-check expression plus several other novel expressions as positive or negative in valence. Half of the adult participant group rated the puffed-cheeks expression as 
positive and half rated it as negative. As the puffed-cheeks expression was not rated more positive than negative, it was chosen as a novel expression reasonably ambiguous in valence. The second adult comparison group $(\mathrm{N}=10)$ freely labeled the puffed-cheeks expression to determine whether the expression was consistently identified as conveying a specific emotion. In response to the question "How does s/he feel?", 3 of the 10 participants labeled the expression as frustrated, and 2 labeled it as overwhelmed. All other labels (angry, bloated, full, nauseous, sick) were generated only once. The varied responses generated for the expression indicated that it was not viewed as conveying any single, specific emotion.

Procedure. Children were randomly assigned to hear one of two novel labels used in the study: pax or tolen.

Animal Labeling. As a familiarization task, and to ensure that children could respond to the experimenter's questions appropriately, children first presented with three animal pictures (cat, dog, rabbit), shown one at a time. For each picture, children were asked "Is this a cat, a dog or a rabbit?" All children correctly chose the animals in the array as requested by the experimenter.

Priming. Children next underwent a priming procedure to increase the accessibility of the emotion labels as well as to introduce the novel label. The experimenter initiated a conversation with the child about feelings and asked questions such as "happy is a feeling; have you ever felt happy?" Children's responses to the experimenter's question were not corrected. The labels targeted in the priming session were those that were to be presented in the study happy, sad/angry, and pax/tolen. Children heard each target label twice before participating.

Word List Task. The male and female poser sets were counterbalanced. Each expression was presented one at a time and children selected a label to describe the poser's feeling. As the 
children in this study were too young to read a list of labels, the experimenter verbally provided the labels for each face, saying: "Is she happy, pax or sad?" For the first set of expressions, children were asked to attribute an emotion to the happy expression first, followed by sad and finally, the novel expression. For the second set of expressions, the order of emotions was again partially random, and the child was presented the novel expression second.

Free Labeling Task. Next, children freely labeled each expression that they saw in the first word list trial. Children were shown each picture one at a time, in a random order, and were asked, "How does he/she feel?" Children were free to give any emotion label they chose.

Scoring. For the word list task, children's responses were coded for whether they matched the expected label with the expected expression (coded as a 1 or 0 ). For each emotion category, children's scores across the two trials were averaged, resulting in a recognition score ranging between 0 and 1. For the free labeling task, children's responses were sorted by three independent coders into one of the following categories: happiness, sadness, anger, fear, surprise, disgust, pride, pax, or tolen. Any responses for which coders could not agree were categorized as other. For responses relevant to the present study, those categorized as correct for happiness were: happy; for sadness were: sad; for pax were: pax, paxes, pack: and for tolen were: tolen.

\section{Results and Discussion}

As shown in Table 1, the majority of children (58\%) matched the novel expression with the novel label. Children could respond in four ways: selecting the happy expression, the sad expression, the puffed cheeks expression, or by saying 'none'. Although children could have responded in four ways, here we use a more conservative baseline level of chance guessing: $33 \%$. This percentage is significantly greater than the .33 that would be expected by chance guessing, as determined by a single sample t-test, $t(23)=2.85, p<.008$. Each child had two 
opportunities to respond that no one in the array felt pax. For only three of these 48 trials did children respond in such a way, or refuse to provide a response.

For the free labeling task, $58 \%$ of children labeled the novel expression with the novel label, as shown in Table 1. Thus, after only a few exposures to the novel expression, children were able to spontaneously generate the label the next time they encountered the expression.

Age and gender effects were also significant. For the word list task, a 3 (age group) x 2 (gender) x 3 (emotion) mixed-design repeated measures ANOVA found a main effect of gender, such that girls were more likely to match the expressions with the expected labels than boys were, $F(1,18)=4.84, p=.04, \eta_{\mathrm{p}}{ }^{2}=.21$. The main effects of age, $F(2,18)=14.08, p<.001, \eta_{\mathrm{p}}{ }^{2}$ $=.61$, and emotion, $F(2,36)=12.74, p<.001, \eta_{\mathrm{p}}{ }^{2}=.41$, were qualified by an age $\mathrm{x}$ emotion interaction, $F(4,36)=6.54, p<.001, \eta_{\mathrm{p}}^{2}=.42$. Three- and four-year-olds showed no differences across emotions in their matching of the expressions and labels, but two-year-olds were less likely to match the expression and label for the novel expression than the happy or sad expressions (all $p$ s $<.001$ ). These effects are identical to those found with non-parametric tests (, see Supplemental Materials).

For the free-labeling task, a 3 (age group) x 2 (gender) x 3 (emotion) mixed-design repeated measures ANOVA found a main effect of gender, such that girls were more likely to label the expressions with the expected labels than boys were, $F(1,18)=4.91, p=.04, \eta_{\mathrm{p}}{ }^{2}=.21$. The main effects of age, $F(2,18)=14.04, p<.001, \eta_{\mathrm{p}}{ }^{2}=.61$, and emotion, $F(2,36)=9.18, p<$ $.001, \eta_{\mathrm{p}}{ }^{2}=.34$, were qualified by an age $\mathrm{x}$ emotion interaction, $F(4,36)=6.65, p<.001, \eta_{\mathrm{p}}{ }^{2}=$ .43. Three- and four-year-olds showed no difference across emotions in labeling the expressions with the expected label, but two-year-olds were less likely to label the novel expression with the 
expected label than they were to label the happy or sad expressions with the expected label (all ps $<.001)$.

Not surprisingly, two-year-olds' performance was low for both tasks: rather than using pax, half of these children matched the novel expression with the label sad in the word list task, and also labeled the novel expression as sad in the free labeling task. This pattern might reflect a recency effect for two-year-olds in the word list task, as the label sad was the last word listed by the experimenter. Alternatively, perhaps two-year-olds have formed a very broad category labeled sad and were willing to assimilate the novel expression into that category; two-year-olds are known to include not only sad expressions but anger and fear expressions under the label sad (Widen, 2013). However, three- and four-year-olds' performance matching the novel label and expression was high. Thus starting at three years of age, children can use a process of elimination to match a novel expression to a novel label presented in a verbal list.

\section{Study 2}

Children matched the novel label with the novel expression presented in Study 1, indicating that children can use a process of elimination to match a single expression to one of several labels. However, in daily life, children may also use a process of elimination to match several expressions to a single label, for example, when a parents says "hmm, he looks sad" while in a crowded room. In addition, 2-year-olds may have displayed a recency effect for the last spoken label in Study 1. Therefore, we conducted a second study using a choice-from-array procedure to determine whether children would continue to rely on the process of elimination to match novel expressions and labels when their choices were presented visually (arrays of expressions), rather than verbally (emotion label lists). Because $30 \%$ of the adult comparison 
group labeled the novel expression as angry (or a close synonym), for half of children we also replaced the sad expression with one of anger, to more strongly test our theory.

\section{Method}

Participants. Participants were 48 children, with 16 children in each of three age groups: two-year-olds $(\mathrm{M}=29.9$ mos., $\mathrm{SD}=2.6$ mos. $)$, three-year-olds $(\mathrm{M}=41.7$ mos., $\mathrm{SD}=3.5$ mos. $)$, and four-year-olds $(\mathrm{M}=52.7$ mos., $\mathrm{SD}=2.6 \mathrm{mos}$.$) . Each age group included an equal number$ of males and females. All children were fluent in English and tested in the greater Boston area.

Materials. The photographs used were the same as those used in Study 1. Also included were expressions of anger, posed by the same male and female adult used in Study 1.

Procedure. Before participating, children were randomly assigned to one of two expression conditions: half of children viewed an array with a sad expression as the negative distractor and the half saw an angry expression. The remainder of the procedure was identical to that of Study 1, with the following exceptions.

Animal Labeling. As a familiarization task, children were first presented an array of three animal pictures: a cat, a dog, and a rabbit. The experimenter asked: "Do you see a cat (dog, rabbit)?" Children were asked to identify each animal in the array once. All children pointed to the correct animals in the array as requested by the experimenter.

Choice-from-array task. For the first array, children viewed three facial expressions which were arranged in random order and remained on the table throughout the trial (happiness, sadness/anger, and puffed-cheeks). The expressions were posed by either a male or a female poser and the order of presentation was counterbalanced. The experimenter asked for emotions in a predetermined order. Children were first asked about the positive expression in the array: "Do you see anyone who feels happy?" This question was phrased in such a way that children 
would not assume that a person displaying the given emotion was in the array. After the child pointed to an expression (or responded that no one felt happy) children were then asked about the negative expression (sad or angry), and finally, pax (or tolen).

For the second array, children viewed the expressions posed by the remaining poser (either male or female, counterbalanced). The order of label presentation was partially random; on the second trial, children were always asked if they saw anyone who felt pax. Pax was presented second so that if children were using a process of elimination to match labels to expressions, they would still have to choose between the two remaining expressions that they had not yet selected. For the first and third trials, children were asked about the positive and negative labels, which were ordered randomly.

Free Labeling Task. Next, children freely labeled each expression that they saw in the first choice-from-array trial.

Scoring. Responses categorized as correct for anger were angry, frustrated, and mad.

\section{Results and Discussion}

As shown in Table 1, the mean recognition score for preschoolers' matching of the novel label with the novel expression was $87 \%$. This percentage is significantly greater than the .33 that would be expected by chance guessing, as determined by a single sample t-test, $t(48)=$ 13.83, $p<.001$. Each child had two opportunities to respond that no one in the array felt pax (or tolen). For none of these 96 trials did children respond in such a way; all children selected an expression from the array for the pax/tolen label.

For the free-labeling task, $44 \%$ of children labeled the novel expression with the novel label (either pax or tolen), as shown in Table 1. This percentage is slightly lower than that in 
Study 1, possibly due to children having heard the novel label (either pax or tolen) only two times during the course of this study, as opposed to eight times in Study 1.

A preliminary 2 (negative expression condition) x 3 (age group) x 2 (gender) x 2 (task) x 3 (emotion) ANOVA showed no influence of the negative expression condition (sad or angry) on children's performance (all $p \mathrm{~s}>$.10). Thus, the expression condition was collapsed, and will not be discussed further.

For the choice-from-array task, a 3 (age group) x 2 (gender) x 3 (emotion) mixed-design repeated measures ANOVA found that children's performance increased with age, $F(2,42)=$ $3.86, p=.03, \eta_{\mathrm{p}}{ }^{2}=.16$. Least Significant Difference (LSD) post-hoc tests showed that two-yearolds' performance was lower than that of the other age groups (all $p$ s <.05). No main effects or interactions for any of these variables emerged; children's performance for the positive, negative and novel expressions did not vary reliably.

For the free-labeling task, a 3 (age group) x 2 (gender) x 3 (emotion) mixed-design repeated measures ANOVA showed that children's labeling of the expressions with the expected label increased with age, $F(2,42)=4.82, p=.01, \eta_{\mathrm{p}}{ }^{2}=.19$. Two-year-olds' performance was lower than that of the other age groups (all $p \mathrm{~s}<.05$ ). As shown in Table 2, children's performance also varied with the emotion presented, with the positive expressions labeled most often, followed by the negative expressions, and finally, the novel expressions, $F(2,84)=2.74, p$ $<.001, \eta_{\mathrm{p}}{ }^{2}=.36($ all $p$ 's $<.004)$. Finally, a three-way age $\mathrm{x}$ emotion $\mathrm{x}$ gender interaction indicated that four-year-old girls were more likely to label the negative expression than fouryear-old boys were, $F(4,84)=3.14, p<.02, \eta_{\mathrm{p}}{ }^{2}=.13$.

In the choice-from-array task, children's performance matching known emotion labels to their associated expressions was indistinguishable from their matching of the made-up 
expression with the made-up label - children were as likely to 'recognize' the pax face as they were to 'recognize' the happy and sad faces. And, unlike Study 1, two-year-olds showed no recency effect; when the options were presented visually in the choice-from-array task (i.e. expressions) rather than verbally as in the word list task (i.e. emotion labels), children as young as two years of age can match a novel label with a novel expression in the choice-from-array task using a process of elimination.

After only a few exposures to the novel label, nearly half of children (including $75 \%$ of four-year-olds) freely labeled the novel expression with the novel label; children again appeared to 'recognize' the emotion presented. Prior to participating in this study, the novel label and novel expression presented were likely unfamiliar to children; presumably preschoolers made the association between the label and the expression during the choice-from-array task.

\section{Conclusion}

Across two studies, seventy-three percent of children selected a novel facial expression in response to questions like "Do you see anyone who feels pax?" They selected the novel expression rather than selecting a happy facial expression, a sad facial expression, or responding "no". Past research indicates that children match happy and sad expressions with their appropriate labels by two years of age (Denham \& Couchoud, 1990; Nelson \& Russell, 2011a, 2011b; Widen, 2013; Widen \& Russell, 2003), and as there was no prior association between the novel expressions presented and the labels children matched to them, it is likely that children used a process of elimination to make this association. Thus, our data are consistent with the idea that when children were presented with a label like pax, they matched it to the expression for which they did not already have a label. 
Our results indicate that children apply a process of elimination strategy to facial expressions, not only to categories like colors or animals, and these findings have broad implications for our understanding of how children acquire expression and emotion category knowledge. That children readily create new expression and emotion categories when presented novel expressions and labels suggests that their pre-conceived expectations regarding expressions are minimal, and are not limited to the six basic expressions or emotion categories. This flexibility may allow children to build categorical knowledge tailored to their immediate environment. Additional research from our lab indicates that two- to ten-year-old children, and some adults, apply this strategy whether the label is familiar or unfamiliar, and regardless of valence, suggesting the strategy remains useful throughout development (Nelson \& Russell, 2015).

These studies provide early evidence that children may build emotion categories using a process of elimination, although questions remain regarding the mechanism that underlies this process. As nearly half of children spontaneously labeled the novel expression with the expected label, it is possible that children directly linked the given label with the novel expression. However, it is also possible that children simply generated a recently heard label when asked to label the novel facial expression. Our findings are consistent with both of these scenarios, and further research must be done to definitively determine which is most likely.

The research presented here may provide insight into the process by which children acquire knowledge about emotional expressions. At some point early in development, presumably, all expressions are novel for children, and none have a known label. The idea that children, once they are familiar with one expression and its label, would use a process of elimination to match other expressions with other labels is consistent with a great deal of 
literature documenting children's use of this strategy in a variety of other situations. Our demonstration that children use this strategy when encountering expressions may shed light on questions about how children acquire emotion category knowledge, and why this process is so protracted (Widen, 2013; Widen \& Russell, 2004); children may need to encounter an expression and label in a given situation in order to employ a process of elimination strategy, thus acquiring expression information gradually, throughout childhood. 


\section{References}

Au, T. K., \& Glasman, M. (1990). The principle of mutual exclusivity in word-learning: To honor or not to honor? Child Development, 61, 1474-1490.

Au, T.K., \& Markman, E.M. (1987). Acquiring word meanings via linguistic contrast. Cognitive Development, 58, 1021-1034.

Baldwin, D. A., Markman, E. M., Bill, B., Desjardins, R. N., Irwin, R. N., \& Tidball, G. (1996). Infants' reliance on a social criterion for establishing word-object relations. Child Development, 67, 3135-3153.

Bialystok, E., Barac, R., Blaye, A., \& Poulin-Dubois, D. (2010). Word mapping and executive functioning in young monolingual and bilingual children. Journal of Cognition and Development, 11, 485-508

Carey, S. (1978). The child as word learner. In M. Halle, J. Bresnan, H.A. Miller (Eds.), Linguistic theory and psychological reality (pp.264-293). Cambridge, MA: MIT Press.

Denham, S. A., \& Couchard, E. A. (1990). Young preschoolers' understanding of emotions. Child Study Journal, 20, 171-192.

Diesendruck, G., Hall, D. G., \& Graham, S. A. (2006). Children's use of syntactic and pragmatic knowledge in the interpretation of novel adjectives. Child Development, 77, 16-30.

Diesendruck, G., \& Markson, L. (2001). Children's avoidance of lexical overlap: A pragmatic account. Developmental Psychology, 37, 630-641.

Ekman, P. (1980). The Face of Man. New York: Garland Publishing, Inc.

Ekman, P., \& Friesen, W.V. (1978). Manual of the Facial Action Coding System (FACS). Consulting Psychologists Press, Palo Alto, CA. 
Graham, S.A., Nilsen, E.S., Collins, S., \& Olineck, K. (2010). The role of gaze direction and mutual exclusivity in guiding 24-month-olds' word mappings. British Journal of Developmental Psychology, 28, 449-465.

Grassmann, S., Stracke, M., \& Tomasello, M. (2009). Two-year-olds exclude novel objects as potential referents of novel words based on pragmatics. Cognition, 112, 488-493.

Halberda, J. (2006). Is this a dax which I see before me? Use of the logical argument disjunctive syllogism supports word-learning in children and adults. Cognitive Psychology, 53, 310344.

Haryu, E., Imai, M., \& Okada, H. (2011). Object similarity bootstraps young children to actionbased verb extensions. Child Development, 82, 674-686.

Herba, C. M., Landau, S., Russell, T., Ecker, C., \& Phillips, M. L. (2006). The development of emotion-processing in children: effects of age, emotion, and intensity. Journal of Child Psychology and Psychiatry, and Allied Disciplines, 47(11), 1098-106.

Izard, C. E. (1994). Innate and Universal Facial Expressions: Evidence From Developmental and Cross-Cultural Research. Psychological Bulletin, 115, 288-299.

Jack, R.E., Blais, C., Scheepers, C., Schyns, P.G., \& Caldara, R. (2009). Cultural confusions show that facial expressions are not universal. Current Biology, 19, 1543-1548.

Jaswal, V. K., \& Hansen, M. B. (2006). Learning words: Children disregard some pragmatic information that conflicts with mutual exclusivity. Developmental Science, 9, 158-165.

Kayyal, M. H., \& Russell, J. A. (2013). Americans and Palestinians judge spontaneous facial expressions of emotion. Emotion, 13(5), 891. 
Kobiella, A., Grossmann, T., Reid, V. M., \& Striano, T. (2008). The discrimination of angry and fearful facial expressions in 7-month-old infants: An event-related potential study. Cognition \& Emotion, 22(April 2015), 134-146. doi:10.1080/02699930701394256

Gendron, M., Lindquist, K., Barsalou, L., \& Barrett, L. F. (2012). Emotion words shape emotion percepts. Emotion, 12, 314-325.

Gendron, M., Roberson, D., van der Vyver, J. M., \& Barrett, L. F. (2014). Perceptions of emotion from facial expressions are not culturally universal: Evidence from a remote culture. Emotion, 14, 251-262.

Gao, X., \& Maurer, D. (2010). A happy story: Developmental changes in children's sensitivity to facial expressions of varying intensities. Journal of Experimental Child Psychology, 107(2),

Lindquist, K. A., Barrett, L. F., Bliss-Moreau, E., \& Russell, J. A. (2006). Language and the Perception of Emotion. Emotion, 6, 125-138.

Lindquist, K.A., Satpute, A.B., \& Gendron, M. (in press). Does language do more than communicate emotion? Current Directions in Psychological Science.

Lindquist, K.A., Gendron, M., Barrett, L.F. \& Dickerson, B.C. (2014). Emotion perception, but not affect perception, is impaired with semantic memory loss. Emotion, 4, 375-387.

Markman, E. M. (1990). Constraints children place on word meanings. Cognitive Science, 14, $154-173$.

Markham, R., \& Adams, K. (1992). The effect of type of task on children's identification of facial expressions. Journal of Nonverbal Behavior, 16, 21-39.

Markman, E. M., \& Wachtel, G. F. (1987). Children's use of mutual exclusivity to constrain the meanings of words. Cognitive Psychology, 20, 121-157. 
Marsh, A., Elfenbein, H.A., \& Ambady, N. (2003). Nonverbal "accents": Cultural differences in facial expressions of emotion. Psychological Science, 14, 373-376.

Martens, J. P., Hamlin, J. K., \& Tracy, J. L. (2013, January). Is pride recognition innate? Developmental origins of understanding the nonverbal pride expression. Poster presented at the annual meeting for the Society for Personality and Social Psychology. New Orleans, LA.

Nelson, N.L. \& Russell, J.A. (2011a). Putting Motion in Emotion: Do Dynamic Presentations Increase Preschooler's Recognition of Emotion? Cognitive Development, 26, 248-259.

Nelson, N. L., \& Russell, J. A. (2011b). Preschoolers' use of dynamic facial, bodily, and vocal cues to emotion. Journal of Experimental Child Psychology, 110, 52-61.

Nelson, N. L., \& Russell, J. A. (2012). Children's understanding of nonverbal expressions of pride. Journal of Experimental Child Psychology, 111, 379-385.

Nelson, N. L., \& Russell, J. A. (2013). Universality revisited. Emotion Review, 5, 8-15.

Nelson, N.L., \& Russell, J.A. (2015). A Facial Expression of Pax: Assessing Children's “Recognition” of Emotion from Faces. Manuscript submitted for publication.

Nelson, N. L., Hudspeth, K., \& Russell, J. A. (2013). A story superiority effect for disgust, fear, embarrassment, and pride. British Journal of Developmental Psychology, 31, 334-348.

Quinn, P. C., Anzures, G., Izard, C. E., Lee, K., Pascalis, O., Slater, a. M., \& Tanaka, J. W. (2011). Looking Across Domains to Understand Infant Representation of Emotion. Emotion Review, 3(2), 197-206.

Roberson, D., Damjanovic, L., \& Kikutani, M. (2010). Show and Tell: The Role of Language in Categorizing Facial Expression of Emotion. Emotion Review, 2(3), 255-260. 
Russell J.A., and Widen S.C. (2002). A label superiority effect in children's categorization of facial expressions. Social Development, 11, 30-52.

Tracy, J. L., \& Matsumoto, D. (2008). The spontaneous expression of pride and shame: evidence for biologically innate nonverbal displays. Proceedings of the National Academy of Sciences of the United States of America, 105(33), 11655-11660.

Waxman, S.R., \& Booth, A.E. (2000). Principles that are invoked in the acquisition of words, but not facts. Cognition, 77, B33-B43.

Waxman, S. R., \& Booth, A. E. (2001). Seeing pink elephants: Fourteen month olds' interpretations of novel nouns and adjectives. Cognitive Psychology, 43, 217-242.

Waxman, S. R., Lidz, J. L., Braun, I. E., \& Lavin, T. (2009). Twenty four-month-old infants' interpretations of novel verbs and nouns in dynamic scenes. Cognitive Psychology, 59, $67-95$.

Waxman, S. R., \& Markow, D. B. (1998). Object properties and object kinds: Twenty-onemonth-old infants' extension of novel adjectives. Child Development, 69, 1313-1329.

Widen, S.C. (2013). Children's interpretation of facial expressions: The long path from valencebased to specific discrete categories. Emotion Review 5 (1), 72-77

Widen, S.C., \& Russell, J.A. (2002). Gender and preschoolers' perception of emotion. MerrillPalmer Quarterly, 48(3), 248-262.

Widen, S. C., \& Russell, J. A. (2003). A closer look at preschoolers' freely produced labels for facial expressions. Developmental Psychology, 39, 114-128.

Widen, S.C., \& Russell, J.A. (2004). The relative power of an emotion's facial expression, label, and behavioral consequence to evoke preschoolers' knowledge of its cause. Cognitive Development, 19(1), 111-125. 
Widen, S.C., \& Russell, J.A. (2010a). The "disgust face" conveys anger to children. Emotion, $10(4), 455$.

Widen, S.C., \& Russell, J.A. (2010b). Children's scripts for social emotions: Causes and consequences are more central than are facial expressions. British Journal of Developmental Psychology, 28, 565-581.

Wierzbicka, A. (1994). Emotion, language, and cultural scripts. In S. Kitayama \& H. R. Markus (Eds.), Emotion and culture: Empirical studies of mutual influence (pp. 133-196). Washington, DC: American Psychological Association. 


\section{Highlights}

- Preschoolers can use a process of elimination to learn about novel facial expressions.

- Children linked a novel expression and label in two different study designs.

- Prolonged expression recognition development may be related to language acquisition. 


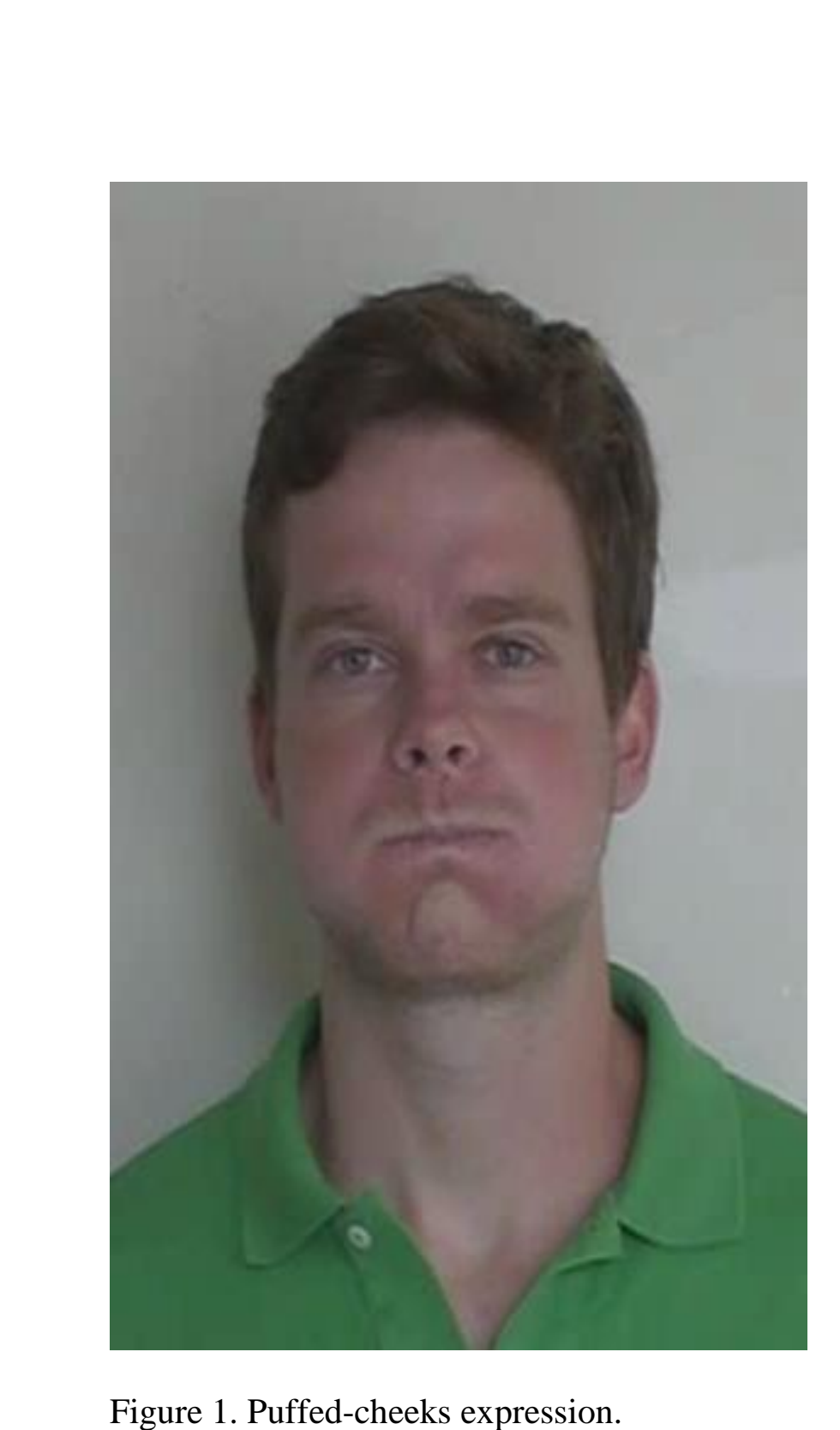

Figure 1. Puffed-cheeks expression.

Figure

Figure 1. Puffed-cheeks expression.

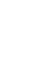

\title{
Figure
}
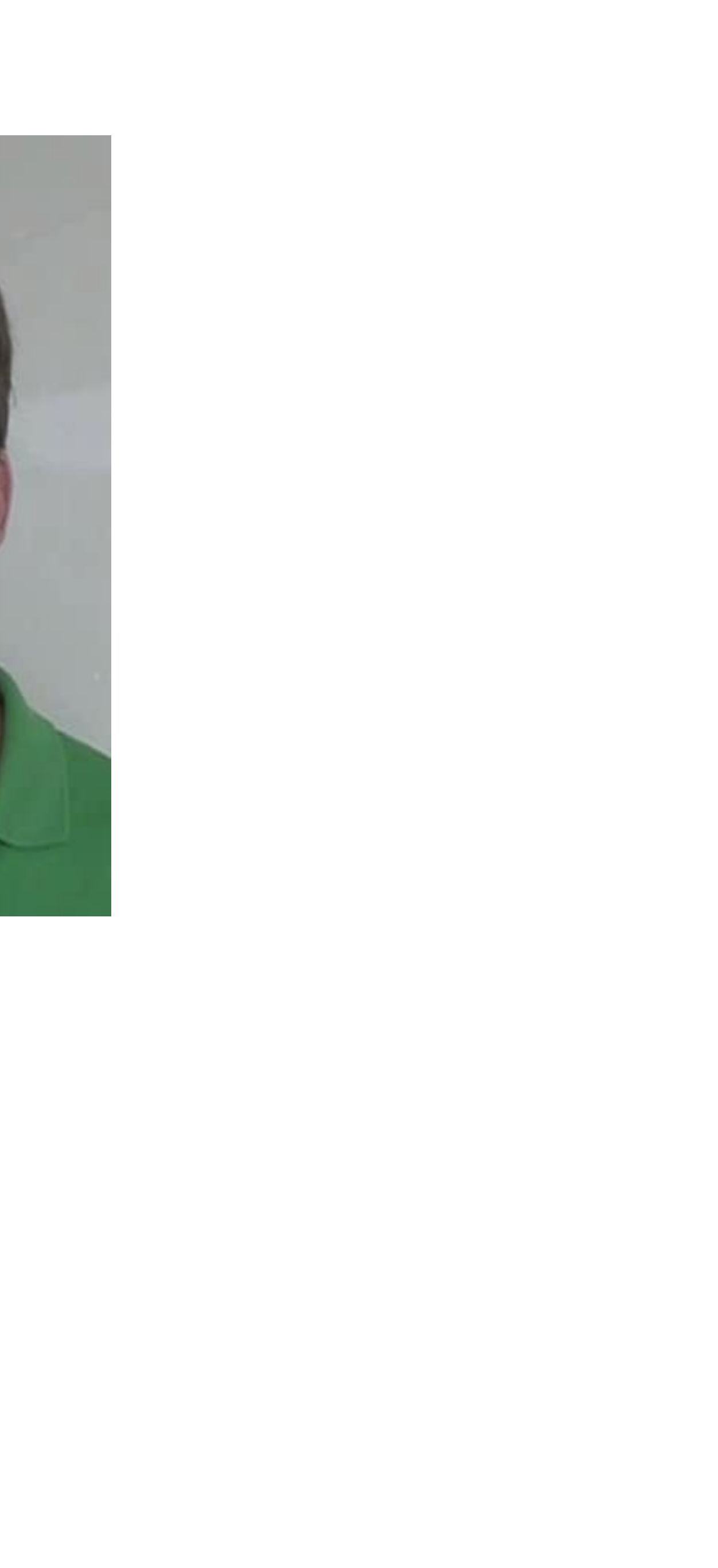
Table 1. Average percentage of trials in which children matched the target label with the puffed-cheeks expression, by age, in each study.

\begin{tabular}{|c|c|c|c|}
\hline & & & \multirow[b]{2}{*}{ Mean } \\
\hline & Study 1 & Study 2 & \\
\hline & Word List Task & $\begin{array}{c}\text { Choice-from-array } \\
\text { Task }\end{array}$ & \\
\hline 2-year-olds & 6 & 78 & 42 \\
\hline 3-year-olds & 75 & 88 & 82 \\
\hline 4-year-olds & 94 & 94 & 94 \\
\hline \multirow[t]{2}{*}{ Mean } & 58 & 87 & 73 \\
\hline & Free Labeling Task & Free Labeling Task & \\
\hline 2-year-olds & 0 & 19 & 10 \\
\hline 3-year-olds & 75 & 38 & 57 \\
\hline 4-year-olds & 100 & 75 & 88 \\
\hline Mean & 58 & 44 & 51 \\
\hline
\end{tabular}

Note. In Studies 1 and 2, the target label was either pax or tolen. 
Table 2. Average percentage of trials in which children matched the expected label and expression, by expression, in each study.

\begin{tabular}{|c|c|c|c|}
\hline & Study 1 & Study 2 & Mean \\
\hline & Word List Task & Choice-from-array Task & \\
\hline Happy & 90 & 92 & 91 \\
\hline Sad/Angry & 90 & 90 & 90 \\
\hline Puffed Cheeks & 58 & 87 & 73 \\
\hline \multirow[t]{2}{*}{ Mean } & 79 & 90 & 85 \\
\hline & Free Labeling Task & Free Labeling Task & \\
\hline Happy & 88 & 92 & 90 \\
\hline Sad/Angry & 88 & 71 & 80 \\
\hline Puffed Cheeks & 58 & 44 & 51 \\
\hline Mean & 78 & 69 & 74 \\
\hline
\end{tabular}

Note. In Studies 1 and 2, the target label was either pax or tolen. 
Click here to download e-component: Supplementary Materials - updated.docx e-component
Click here to d

x

(n)

$\sqrt{2}$

(1)

(1)

(1)

(1)

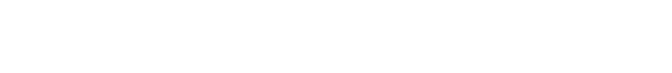

(1)
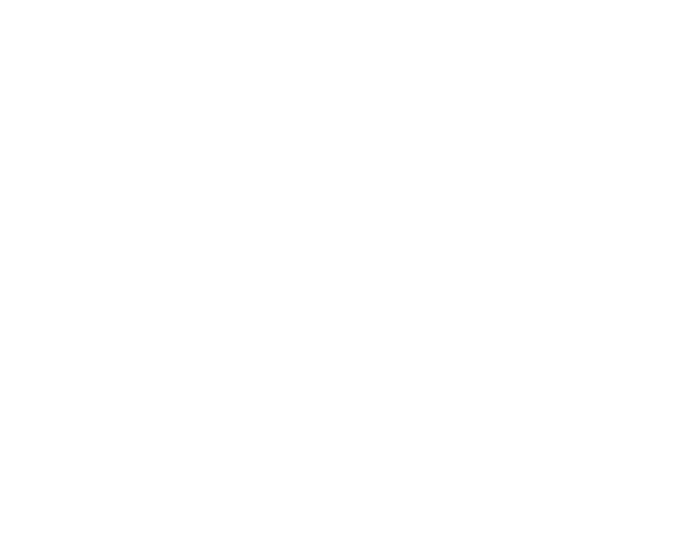